\title{
Heating of thick-walled steam header - an experimental study
}

\author{
Tomasz Sobota ${ }^{1, *}$ \\ ${ }^{1}$ Cracow University of Technology, Institute of Thermal Power Engineering, Faculty of Mechanical Engineering, \\ Al. Jana Pawła II 37, 31-864 Cracow, Poland
}

\begin{abstract}
The paper presented the description of the experimental installation for testing of the computer systems for on-line monitoring of the power boilers operation. The results of the experiment can be used for calculation of temperature and thermal stresses distribution in thick walled pressure elements based on the solution of the inverse heat conduction problem.
\end{abstract}

\section{Introduction}

The Polish power plants, in the vast majority, operate power units installed 25 years ago or earlier. Therefore, in the near future thermal power plants facing the need to solve two major problems:

1. Assessment of the degree of usage of the major power plant equipment including boilers, turbines and steam pipelines. Proper estimation of pressure elements damage ratio of power units allows to decide on exchange used elements or decommissioning whole power unit.

2. The increase in the efficiency of electricity generation, including the efficiency of steam boilers already in use and newly built. On-line monitoring of the power boilers operation will reduce the unit cost of electricity production (the cost of $1 \mathrm{kWh}$ of electric energy generation).

Institute of Thermal Power Engineering Cracow University of Technology developed and implemented in several domestic power plants two computer systems for on-line monitoring power boiler operation - Thermal Limitation Block (BOT) and Efficiency Limitation Block (BOS) [1-9].

Thermal Limitations Block allows for safe and quick start-up and shutdown of power boilers, resulting in reduced start-up losses while the high durability of boiler pressure parts is maintained. Block Efficiency Limitations (BOS) allow for power boiler operation with high efficiency and automatic cleaning of the heating surfaces of the combustion chamber and the steam super heater with sootblowers.

Further implementation of the developed systems in the domestic power plants, will enable to increase its competitiveness to foreign electricity producers. In order to further development of the monitoring system experimental installation named Installation for testing computer systems for on-line monitoring of power boilers operation. This installation enables to conduct the research and development in conditions similar to those that exist in steam boilers installed in the power plants [10-14].

\section{Description of the experimental installation}

In order to further development and improvement of the computer systems for on-line monitoring of power boiler operation in the laboratory of the Division of Thermal Power Engineering Cracow University of Technology modern experimental installation was built (Fig. 1). During its construction, particular emphasis was placed on ensuring that the conditions are similar to those that may occur in pressure components installed in power plants. In addition to metal temperature, temperature, mass flow rate, and pressure of the steam were measured as a function of time.

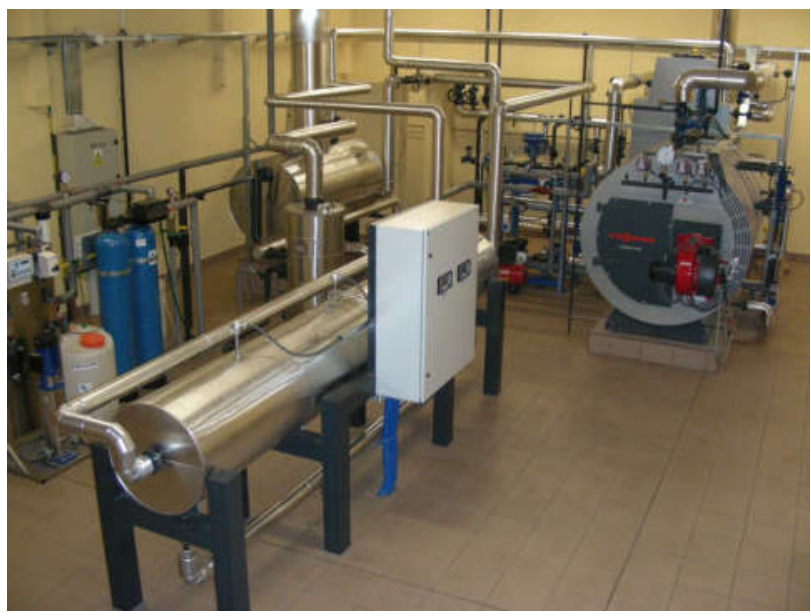

Fig. 1. View of the experimental installation for testing the computer system for on-line monitoring thick-wall pressure components

To measure temperature distribution on the outer surface of the steam header pre-calibrated thermocouples were

\footnotetext{
*Corresponding author: tsobota@mech.pk.edu.pl
} 
used. The experimental installation consists of the following elements:

- steam generation unit with steam output capacity $700 \mathrm{~kg} / \mathrm{h}$, equipped with a three-stage oil burner,

- installation for boiler feed water treatment,

- tray-type (cascade-type) deaerator,

- blow down flash-vessel for heat recovery,

- steam pressure reduction station 10 bar /4 bar /2 bar,

- boiler control system, steam header made of martensitic high alloy P91 steel.

\subsection{Steam header}

The steam header was made out of the martensitic high alloy P91 steel with the following physical properties: specific heat, $c=486 \mathrm{~J} /(\mathrm{kg} \cdot \mathrm{K})$, thermal conductivity, $k=$ $29 \mathrm{~W} /(\mathrm{m} \cdot \mathrm{K})$, density, $\rho=7750 \mathrm{~kg} / \mathrm{m}^{3}$, modulus of elasticity, $E=2,28 \cdot 10^{11} \mathrm{~Pa}$, Poisson's ratio, $v=0,29$, coefficient of thermal expansion $\beta=0,098 \cdot 10^{-4} 1 / \mathrm{K}$. The outer diameter $d_{\text {out }}$, wall thickness $\delta$ and the length $L$ are: $355 \mathrm{~mm}, 50 \mathrm{~mm}$ and $3765 \mathrm{~mm}$, respectively (Fig. 2).

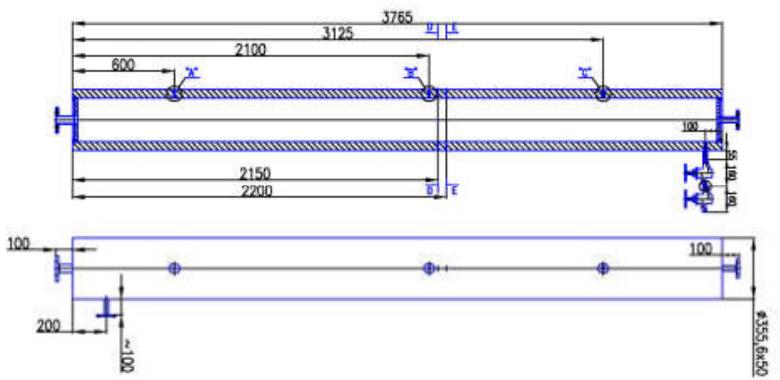

Fig. 2. Diagram of the steam header; A, B, C - location of industrial thermometers, przekrój D-D - the location of the 13 $\mathrm{K}$-type thermocouples on the half of the outer circumference, przekrój E-E - temperature measurement on the wall thickness at four different depths a)

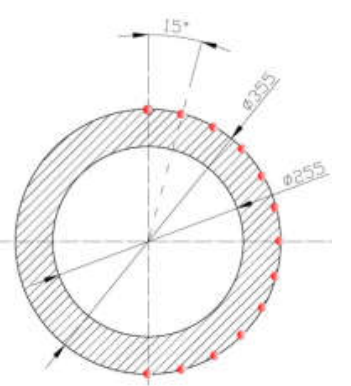

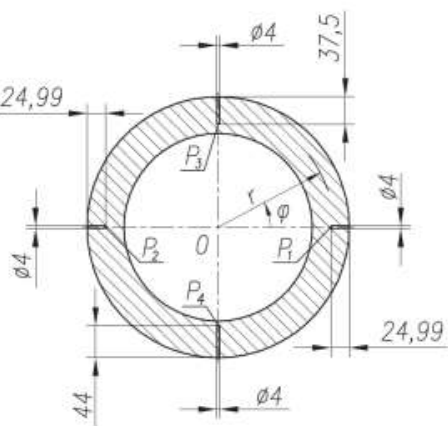

Fig. 3. Location of temperature sensors on the steam header a) thermocouples at the outer surface of the steam header, b) location of interior thermocouples used for experimental validation of the inverse procedure

Thirteen thermocouples NiCr-NiAl (K-type) were mounted every $15^{\circ}$ on the half of the outer circumference at the distance of $2150 \mathrm{~mm}$ from the inlet of steam (Fig. 3a). The temperature measurement on the outer surface of the steam header will be used to determine the temperature distribution on wall cross- section and stress distribution on the inner and outer surfaces of the header using the inverse heat conduction methods.

To validate results of calculation based on the inverse procedure, temperature measurements carried out with four K-type thermocouples, with outer diameter of 3 $\mathrm{mm}$, installed at the interior locations: $\delta_{1}=\delta_{2}=d_{\text {out }}-$ $0,50 \delta, \delta_{3}=d_{\text {out }}-0,75 \delta$ and $\delta_{4}=d_{\text {in }}+6 \mathrm{~mm}$ (Fig. 3b) are used.

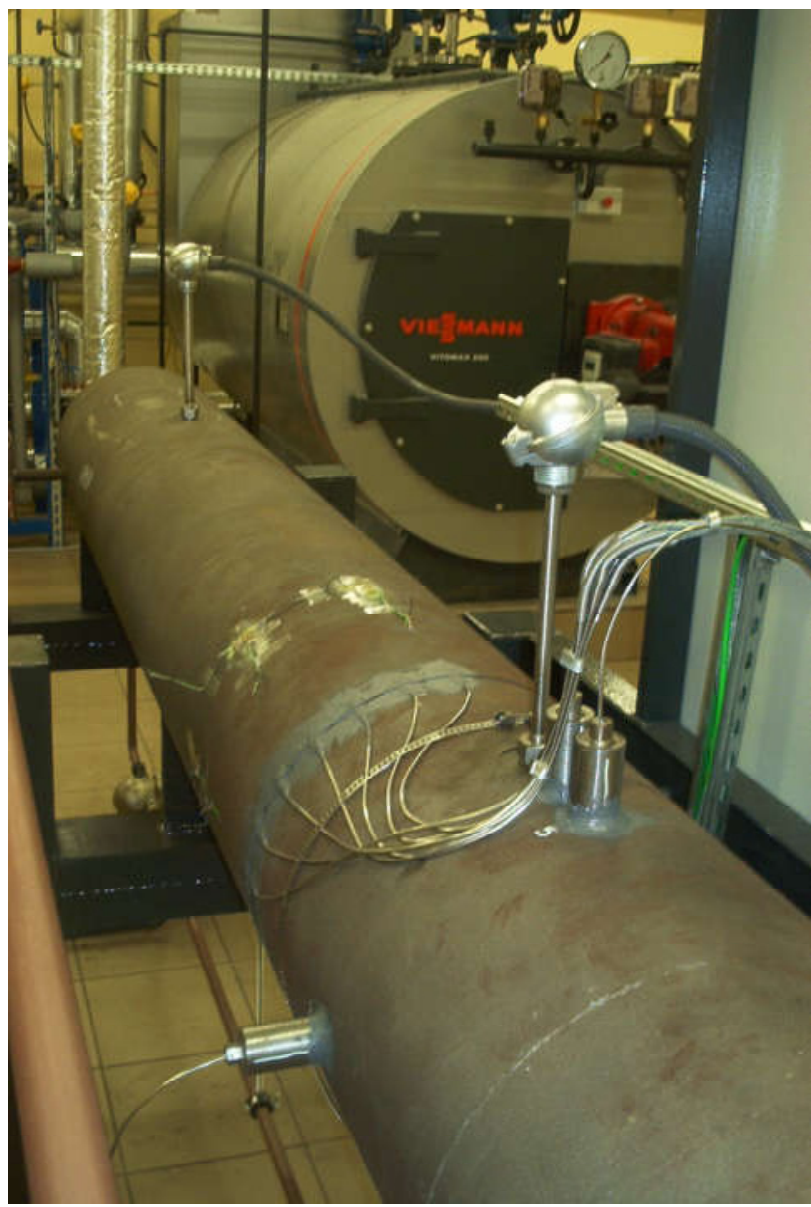

Fig. 4. View of the instrumented steam header before the foundation of the thermal insulation

At the top forming the steam header, at a distance of 600 $\mathrm{mm}$ (point A), $2100 \mathrm{~mm}$ (point "B"), and $3125 \mathrm{~mm}$ (point "C") from steam inlet (Fig. 2), 3 through-holes were drilled and threaded, in which industrial thermometers in massive housings made of steel 1H18N9T was placed. Implemented with their assistance saturated steam temperature measurement will be used to develop and to test methods for measuring the temperature of the medium flowing at high speed. The developed in the future method allows determining the actual temperature of the medium, on which the inertia caused by the massive thermometer housing will not affect. 


\section{Results of the experiment}

The measurements were carried out in a transient state. The steam mass flow rate through the steam header was varying during the experiment. During the experiment, the following data were collected using data acquisition system: the temperature at the outer surface of the steam header, wall temperature at the three different depth and steam mass flow rate and its pressure at the header inlet. As the result of conducted experiment time distributions of the temperature at the steam header's outer surface half of the circumference (Fig. 5), internal wall temperature (Fig. 6) and steam temperature, pressure and mass flow rate (Fig. 7) during start-up, operation and shut down were collected.

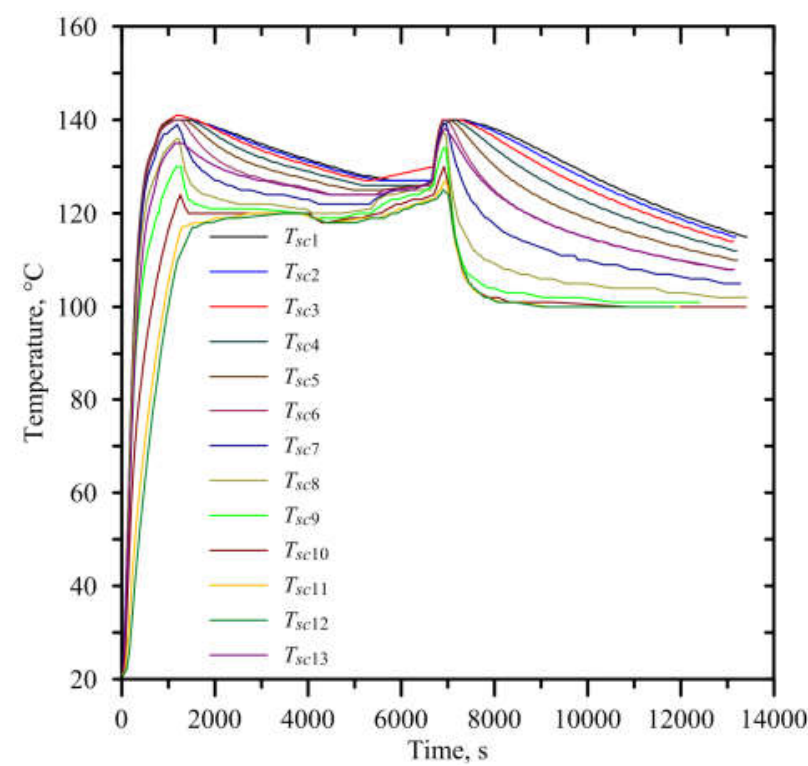

Fig. 5. Time changes of the measured temperature at the steam header's outer surface

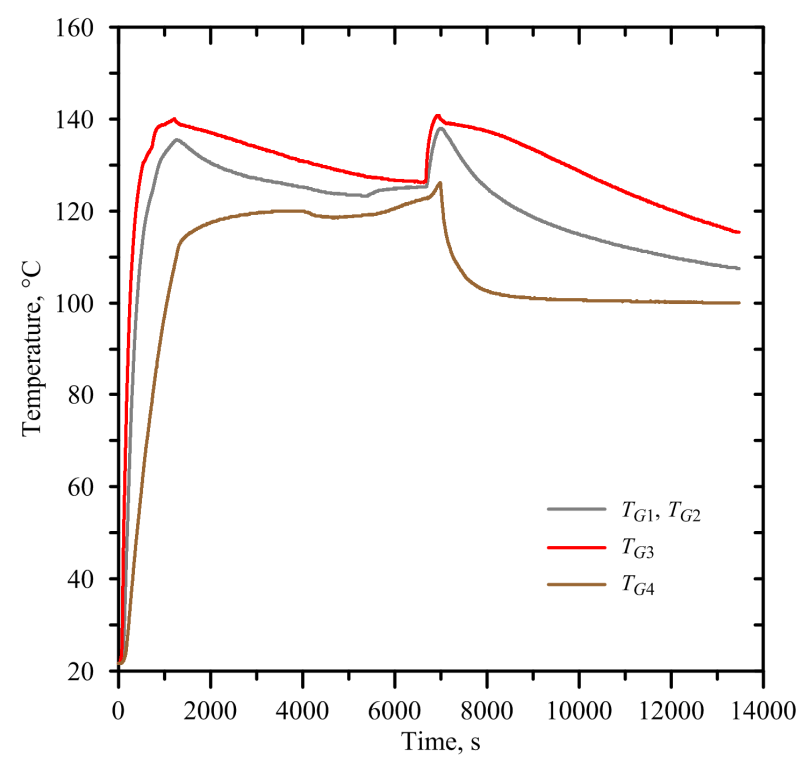

Fig. 6. Measured time changes of the wall temperature at the interior points

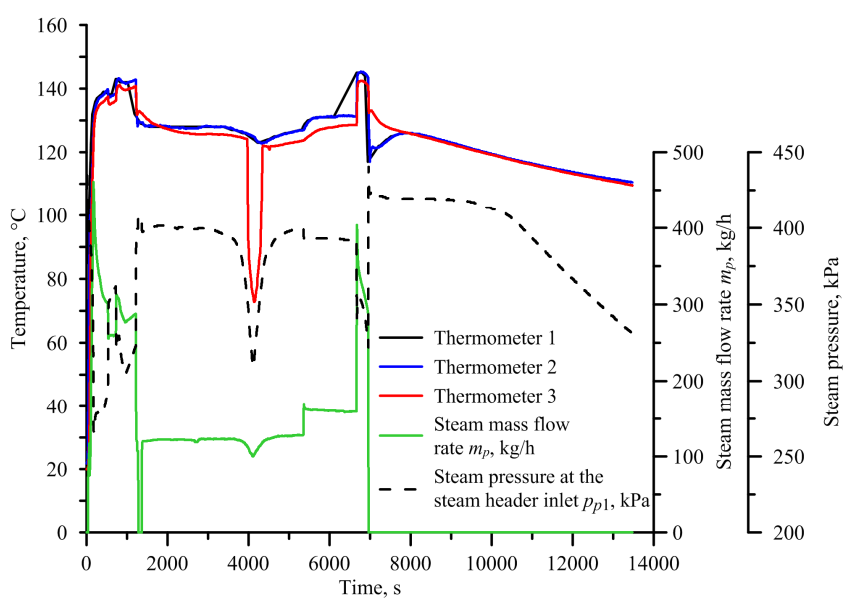

Fig. 7. Time changes of steam temperature, pressure and mass flow rate during the experiment

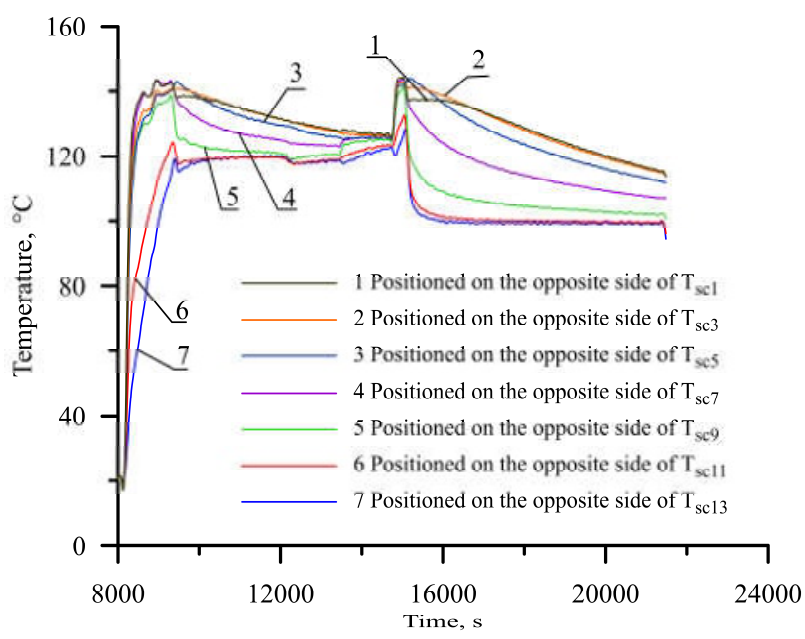

Fig. 8. Time changes of the calculated temperature at the steam header's inner surface

The results of experiments can be used for calculation of temperature and thermal stresses distribution in thick walled pressure elements based on the solution of the inverse heat conduction problem [1$3]$.

\section{Conclusion}

The paper presented the description of the experimental installation for testing of the computer systems for on-line monitoring of the power boilers operation. The results of the experiment are also presented. Developed at the Division of the Thermal Power Engineering Cracow University of Technology and tested in the described in the paper installation computer systems allow for quick to start-up and shutdown of the power boilers, their safe operation with high efficiency and automatic cleaning of heating surfaces of the combustion chamber and the steam super heaters with sootblowers. 


\section{References}

1. J. Taler, D. Taler, K. Kaczmarski, P. Dzierwa, M. Trojan, T. Sobota, Energy, 160, 500-519 (2018)

2. T. Sobota Tomasz, Heat Transfer Eng., 39(13-14), 1260-1271 (2018)

3. T. Sobota, E3S Web of Conferences, 13, (2017)

4. T. Sobota, E3S Web of Conferences, 14, (2017)

5. J. Taler, B Węglowski, W. Zima, P. Duda, S. Grądziel, T. Sobota, A. Cebula, and D. Taler, Proc. IMechE 222 Part A: J. Power and Energy, 11-24 (2008)

6. J. Taler, S. Gądziel, T. Sobota, D. Taler, Archiwum Energetyki, XXXVIII(1), 97-122 (2008)

7. S. Lubecki, D. Taler, T. Sobota, Archiv. of Thermodynamics, 29 (4), 87-96 (2008)

8. J. Taler, Sz. Lubecki, T. Sobota, Energetyka, 2-3, 680-681 (2011)

9. J. Taler, B. Węglowski, T. Sobota, D. Taler, M. Trojan, P. Dzierwa, M. Jaremkiewicz, M. Pilarczyk, Proc. of the ASME 2016 Power Conference POWER2016, (2016)

10. T. Sobota, Testing station for computerized systems for continuous monitoring of power boilers' operation, in Modern Power Systems and Units, J. Taler (Ed.) (Wydawnictwo Politechniki Krakowskiej, Kraków, 577-586, 2007)

11. M. Jaremkiewicz, D. Taler, T. Sobota, Int. J. of Thermal Sci., 87, 241-250 (2015)

12. M. Jaremkiewicz, D. Taler, T. Sobota, App. Thermal Eng., 29, pp. 3374-3379 (2009)

13. J. Taler, B. Węglowski, D. Taler, T. Sobota, P. Dzierwa, M. Trojan, P. Madejski, M. Pilarczyk, Energy, 92(1), 153-159 (2015)

14. J. Taler, D. Taler, T. Sobota, P. Dzierwa, Archiv. of Thermodynamics, 32 (3), 103-116 (2011) 